\title{
Nutritional options and implications for maximum growth rate of steers
}

\author{
G.P. COSGROVE ${ }^{1}$, P.D. MUIR ${ }^{2}$ and M.G. LAMBERT ${ }^{1}$ \\ ${ }^{1}$ AgResearch Grasslands, Private Bag 11008, Palmerston North \\ 2 AgResearch Poukawa, P O Box 8144, Havelock North
}

\section{A bstract}

Estimates of age and weight at mature size are required for the development of decision-support and mathematical models to describe beef growth. Interim results from an experiment designed to quantify the liveweight gain of steers from weaning to mature size are reported in this paper. Three groups of 28 steers have been fed for 2 years from weaning ( 8 months) to 32 months of age on the following treatments: resident, ryegrass-white clover based pasture (R); a high quality pasture option based on annual ryegrass in winter and spring, and red clover and lotus in summer and autumn (HQ); and a 70\% maize grain : $30 \%$ silage diet offered under feedlot conditions (F). Average daily gains from weaning to 30 months of age and liveweight at 30 months were $0.69 \mathrm{~kg} / \mathrm{hd} /$ day, and $709 \mathrm{~kg}, 0.78 \mathrm{~kg} / \mathrm{hd} / \mathrm{day}$ and $772 \mathrm{~kg}$, and 0.91 $\mathrm{kg} / \mathrm{hd} /$ day and $858 \mathrm{~kg}$ for R, HQ and F treatments, respectively. Feedlot steers had a greater fat depth over the 12113th rib than either of the pasture fed treatments, when measured at the same age. In addition, both pasture groups have shown seasonality in liveweight gain, with periods of low liveweight gain in late autumn and winter of the second and third years. Results are discussed in relation to the nutritional contrasts between treatments.

K eywords: feedlot, cattle, liveweight gain, potential growth

\section{Introduction}

Development of models to describe beef growth mathematically and provide decision support capability for New Zealand conditions is limited by the lack of data on the upper limits to liveweight gain that can be sustained for long periods by beef animals growing to maturity (Rollo et al. this proceedings). Interpretation of most liveweight gain data is confounded by periods of limiting nutrition, whether deliberately applied as a treatment or simply as a consequence of seasonal pasture growth (e.g., Cosgrove \& Brougham 1988). Also the relatively short-term duration of many trials, based on seasonal (e.g., Clark 1991; Goold \& Weeda 1985) or annual production results (Croy \& Weeda 1974), gives no information on age or weight at maturity. These limitations of existing data can be explained in part by commercial and research interest in emphasising gain per unit area rather than gain per animal, in order to conduct trials within a framework of economic relevance. Numerous grazing trials have been conducted using a systems approach, in which animal liveweight gain has been used to reflect effect of treatment modifications of the normal seasonal variation in pasture growth (e.g., Webby et al. 1990), and other long-term trials have been conducted under commercial feeding conditions (e.g., Morris et al. 1990). However, we know of no studies that have ensured a high, "non-limiting" level of nutrition consistently throughout all seasons in a long-term trial.

The increasing emphasis on meeting specified carcass quality (e.g., weight, timing of supply, meat and fat characteristics) criteria for beef marketing (Forgie 1993; Purchas 1993) requires a new emphasis on defining the growth of individuals, rather than growth averaged over individuals in herds (Webby et al. 1993). In addition, high daily gains are an important component of maximising efficiency of beef production (McCall \& Marshall 1991; Wright 1993). The objective of the trial is to define the growth path to mature size, by measuring liveweight gain and feed intake, and age and weight at mature size, of individuals growing at their maximum rate. Nutritional treatments, and large and small genotype contrasts, were incorporated to increase the robustness of the data. This paper reports interim results, obtained over the first 2 years of the trial starting with 8-monthold weaners in May 1993. Results on liveweight gain and aspects of body growth, in relation to feeding conditions, are considered here.

\section{$M$ aterials and methods}

\section{Design}

Eighty-four weaner steers, equal numbers of Simmental and Angus, were obtained from commercial sources in early autumn 1993. They were chosen to represent large and small mature size genotypes, respectively. Some were obtained directly from farms with some knowledge of age and rearing history, while others were obtained 
through saleyards. At purchase, all steers were transferred to the AgResearch Poukawa Research Station in central Hawke's Bay and grazed as a single group on pasture. In mid May 1993, steers were weighed and allocated to 3 nutritional treatments of 28 steers. Each group was balanced for liveweight and breed.

Resident pasture $(R)$ : generally ryegrass-white clover dominant but containing a significant proportion of other grasses and considered typical of beef farm pasture.

High quality forage $(H Q)$ : consisting of annual ryegrass (cv. Grasslands Tama) for feeding in winter and spring (May-October) and a combination of red clover (cv. Grasslands Colenso) and lotus (cv. Grasslands Goldie), sown as monocultures in alternating drill-width strips for feeding in summer and autumn (October-May).

Feedlot $(F)$ : where the feed offered comprised maize grain $(70 \%)$ and pasture silage (30\%).

\section{M easur ements}

Liveweight gain was assessed from regular 2-weekly weighing (unfasted). From spring 1994, measurements on additional parameters of growth (height at withers, and girth), were begun when it was observed that during a prolonged period of static LW over late autumn and winter in the pasture treatments steers continued to "grow". Steers were ultra-sound scanned at 30 months of age to determine fat depth over 12/13 rib.

Monthly calibration cuts were used to develop linear regressions between rising-plate height and mass above ground level for each pasture treatment, and separately for pre- and post-grazing mass estimation. Pasture allocation decisions were based on height recorded by a rising-plate meter, and converted to herbage mass using the regression relationships. Post-grazing height was used to estimate residual herbage mass.

\section{$M$ anagement}

In mid May 1993, the two pasture-based treatments were transferred to the AgResearch Aorangi Lowland Research Area near Palmerston North and the third group placed on the feedlot at AgResearch's Poukawa Research Station near Hastings. During autumn 1994, the pasture-fed steers were transferred from Aorangi to the AgResearch Flock House Research Station. At both Aorangi and Flock House, pasture treatments were grown on predominantly Kairanga series soil types. Steers in each nutrition group consisted equally of the two genotypes, i.e., 14 Angus and 14 Simmental. However, in this paper breed effects are not considered and genotype means for liveweight (LW) and liveweight gain (LWG) are used.
The principle of the trial was to ensure steers were fed ad lib. Steers on pasture treatments were allocated fresh feed 2-3 times per week according to a feed budget, allowing $1 \mathrm{~kg}$ pasture dry matter $/ 10 \mathrm{~kg} \mathrm{LW/}$ day, i.e., $10 \%$ of LW. Criteria of minimum pre-grazing pasture mass (3000 kg DM/ha) and pasture height $(25 \mathrm{~cm})$ were imposed to ensure accessibility did not limit'daily intake. Seasonal pasture growth was modified to a limited degree through the use of inputs, such as irrigation and nitrogen fertiliser. Management practices, such as mechanical topping, conservation, and cleanup grazing by non-trial animals, were used to ensure as far as possible that vegetative leafy growth was offered. Despite the use of these strategies there was natural variation in botanical composition of the resident pasture, and in the proportion of stem and dead material of both treatments. Following adjustment to feedlot conditions over the first few months, steers on the feedlot were fed ad lib. grain and silage by offering sufficient feed daily to allow for 5\% refusals. These steers were confined in large pens, on a concrete base with a litter covering. Feed was allocated once daily, and water was continuously available.

Animal health: Steers were drenched at 6-weekly intervals through the first year of the trial and again in September 1994 at approximately 2 years of age. They received a slow-release trace element bolus in winter 1993 and $\mathrm{Cu}$ by injection on 10 August 1994 and 12 April 1995. A separate pour-on treatment for lice control was applied on 27 July 1994. At the first transition from annual ryegrass to red clover-lotus in October 1993, one steer died of bloat. Following this, steers on this treatment were dosed with slow-release rumensin capsules (90-day effective protection) on 13 October, and again on 19 January. Steers on both grazing treatments received rumensin capsules on 6 October 1994 and 18 January 1995. Other procedures have been adopted as necessary; for example, grazing steers were vaccinated against pink eye in November 1994.

Transitional feeding arrangements for high quality treatment steers: In spring 1993 and 1994, steers on the HQ forage treatment made an abrupt transition from annual ryegrass to red clover-lotus. However, in autumn 1994 and 1995 the reverse transition from red cloverlotus to annual ryegrass was progressive and required the addition of some supplementary feed. The pregrazing height of the red clover-lotus declined to low levels before the annual ryegrass was tall enough for grazing. In 1994 this transition coincided with the relocation from Aorangi to Flock House. Steers on HQ pasture were shifted to Flock House in two equal groups 
on 21 April and 9 June. Resident pasture steers were moved to Flock House on 7 July 1994. From 10 June until 10 August, the HQ steers grazed on resident pasture (allocated at the prescribed rate), and from early July were supplemented with $5 \mathrm{~kg} D \mathrm{DM} / \mathrm{hd} /$ day of pasture baleage, and $3 \mathrm{~kg} / \mathrm{hd} / \mathrm{day}$ of maize grain to raise the energy content of their diet. In 1995, supplementary feeding with red clover baleage began in April.

\section{R esults}

Liveweight gain for the three nutritional treatments is reported for the 21-month period from mid May 1993 to early March 1995. The Angus steers on the feedlot were slaughtered in mid March 1995 after having reached an apparent mature size, based on static LW for approximately 2 months.

Over this period, feedlot steers averaged $0.91 \mathrm{~kg}$ LWG/hd/day to reach $858 \mathrm{~kg} \mathrm{LW}$ at approximately 30 months of age (Table 1). The $\mathrm{R}$ pasture steers gained $0.69 \mathrm{~kg} / \mathrm{hd} / \mathrm{day}$ and those on $\mathrm{HQ}$ pasture gained $0.78 \mathrm{~kg} /$ hd/day, reaching LWs of $709 \mathrm{~kg}$ and $772 \mathrm{~kg}$, respectively. From early March to mid May 1995 the LWG of pasture steers was $0.40 \mathrm{kglhdlday}$ and $0.17 \mathrm{~kg}$ / hd/day for $\mathrm{R}$ and $\mathrm{HQ}$ steers, respectively. This poor autumn growth reduced the overall gains and the difference between the pasture treatments. At mid May 1995, LWG for the two-year period was 0.66 and $0.71 \mathrm{~kg} / \mathrm{hd} /$ day for $\mathrm{R}$ and $\mathrm{HQ}$ steers, respectively.

Table 1 Effect of feeding regime on liveweight gain from weaning and maturity characteristics of steers at 30 months of age.

\begin{tabular}{|c|c|c|c|c|c|}
\hline Feed & $\begin{array}{l}\text { Liieweight } \\
\text { gain } \\
\mathrm{kg} / \mathrm{hd} / \mathrm{day}\end{array}$ & $\begin{array}{l}\text { Live- } \\
\text { weight } \\
\mathrm{kg}\end{array}$ & $\begin{array}{l}\text { Height } \\
\mathrm{c} \mathrm{m}\end{array}$ & $\begin{array}{c}\text { Girth } \\
\mathrm{cm}\end{array}$ & $\begin{array}{c}\text { Fat } \\
\text { depth } \\
\mathrm{m} \mathrm{m}\end{array}$ \\
\hline Resident pasture & 0.69 & 709 & 136.9 & 215.1 & 12.0 \\
\hline Red clover/lotus-Tama & 0.70 & 772 & 138.2 & 223.3 & 15.3 \\
\hline Feedlot & 0.91 & 658 & 137.3 & 243.5 & 28.0 \\
\hline $\begin{array}{l}\text { Statistical contrasts } \\
\text { Feedlot vs grazing }\end{array}$ & 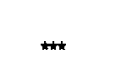 & $\# 1$ & NS & whth & \\
\hline Resident vs Red clover & $* * *$ & & NS & ** & \\
\hline
\end{tabular}

\section{0 , $=P<0.01$ and $P<0.001$, respectively}

NS = not significant

The pattern of LWG differed between the feedlot and grazing treatment groups (Figure 1). Feedlot steers showed consistent LWG throughout the trial with no apparent seasonal variation. In contrast, steers on pasture treatments exhibited periods of no LWG and even short-term weight loss during autumn-early winter

Figure 1 Effect of feeding regime on cumulative liveweight gains of steers from the start of the trial to May 1995 (pasture treatments) or to March 1995 (feedlot). SE represents mean standard error of liveweight for each treatment over 6-month intervals.

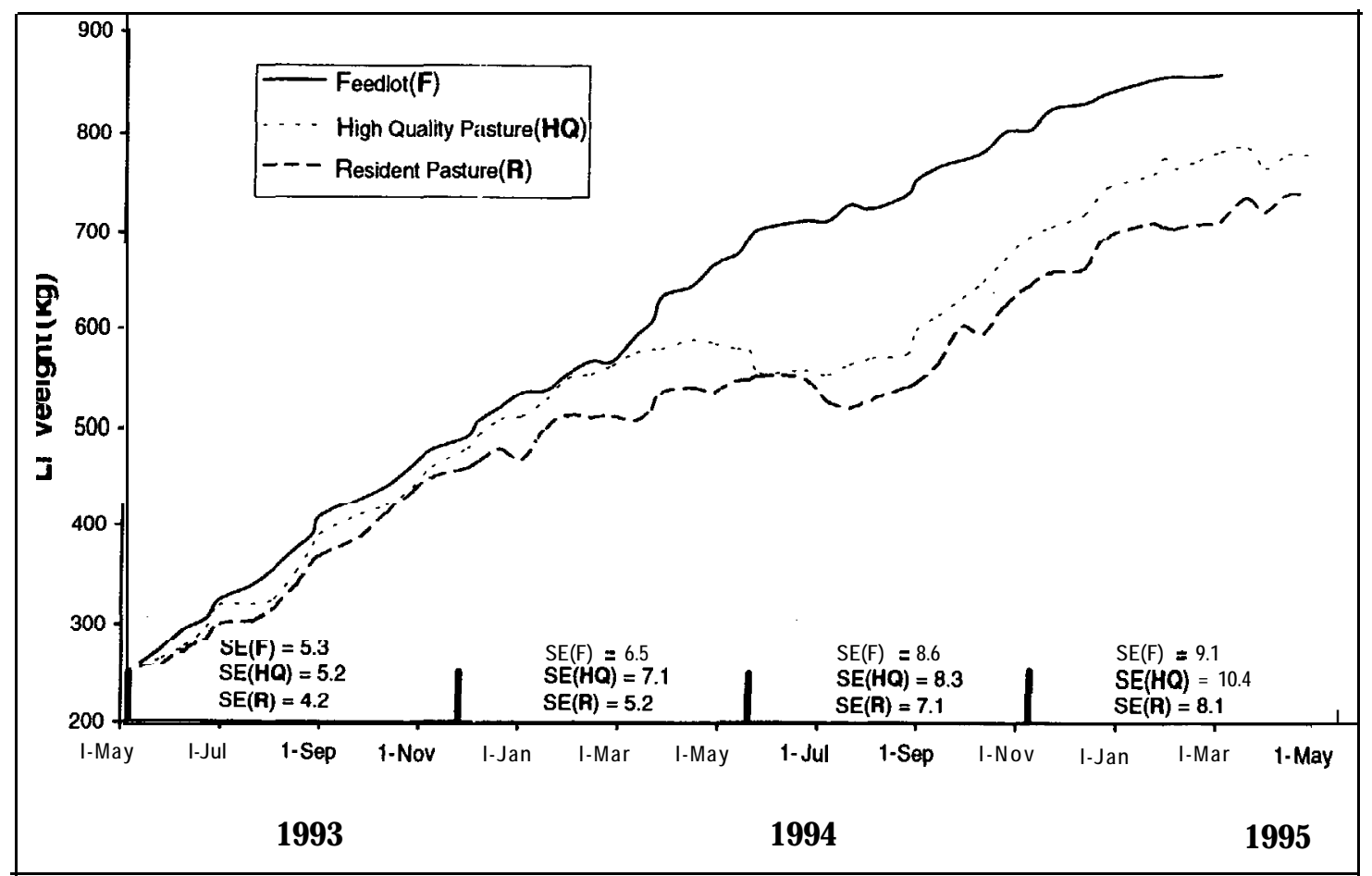


in each year of the trial. Steers grazing HQ forage reached a peak in LW in mid April 1994, and this LW was not regained until mid' September. Steers grazing resident pasture reached a corresponding peak LW approximately 1 month later in mid June and had recovered this LW by mid September. A similar pattern occurred for autumn-winter 1995. This growth stasis was not apparent early in the trial, when grazing steers gained weight through their first autumn-winter following weaning.

\section{Other parameters of steer growth}

For steers at the same age, but at different LW, feeding treatment did not affect height at withers (Table 1). Steers on feedlot had a larger girth than grazing steers and a greater fat depth over the 12/13th rib (Table 1). Similarly, steers on HQ forage had a larger girth than those on resident pasture, but the contrast in fat depth between the two pasture treatments was smaller than between feedlot and pasture.

\section{Pasture conditions}

Figures $2 \mathrm{a}$ and $\mathrm{b}$ summarise on a monthly basis the pre-grazing herbage height and herbage mass of both pasture treatments. Results for the HQ treatment are incomplete for winter 1994 because of the transitional feeding arrangements necessary for this group. Pregrazing herbage mass has consistently been maintained at or above the minimum target level of $3000 \mathrm{~kg} \mathrm{DM} /$ ha for both the resident pasture treatment and the annual ryegrass (winter) and red clover-lotus (summer) components of the HQ forage treatment. However, pregrazing herbage height, also a critical component of the ability of grazing animals to maximise daily intake, was at the minimum target for the resident pasture, and below target for the red clover-lotus over April-May 1994. While no minimum targets for post-grazing height and mass were set, residuals were generally high (Figures $2 c$ and $d$ ) and steers were consuming only a low proportion of the total herbage on offer.

Figure 2 Pre-grazing herbage height and herbage mass ( $a$ and $b$ ), and post-grazing herbage height and herbage mass ( $c$ and $d$ ), for resident $(\square)$ and high quality pasture treatments $(\square)$. SE represents mean standard error of all estimates within a month. Where SE bars are not visible they are less than the size of the symbol.
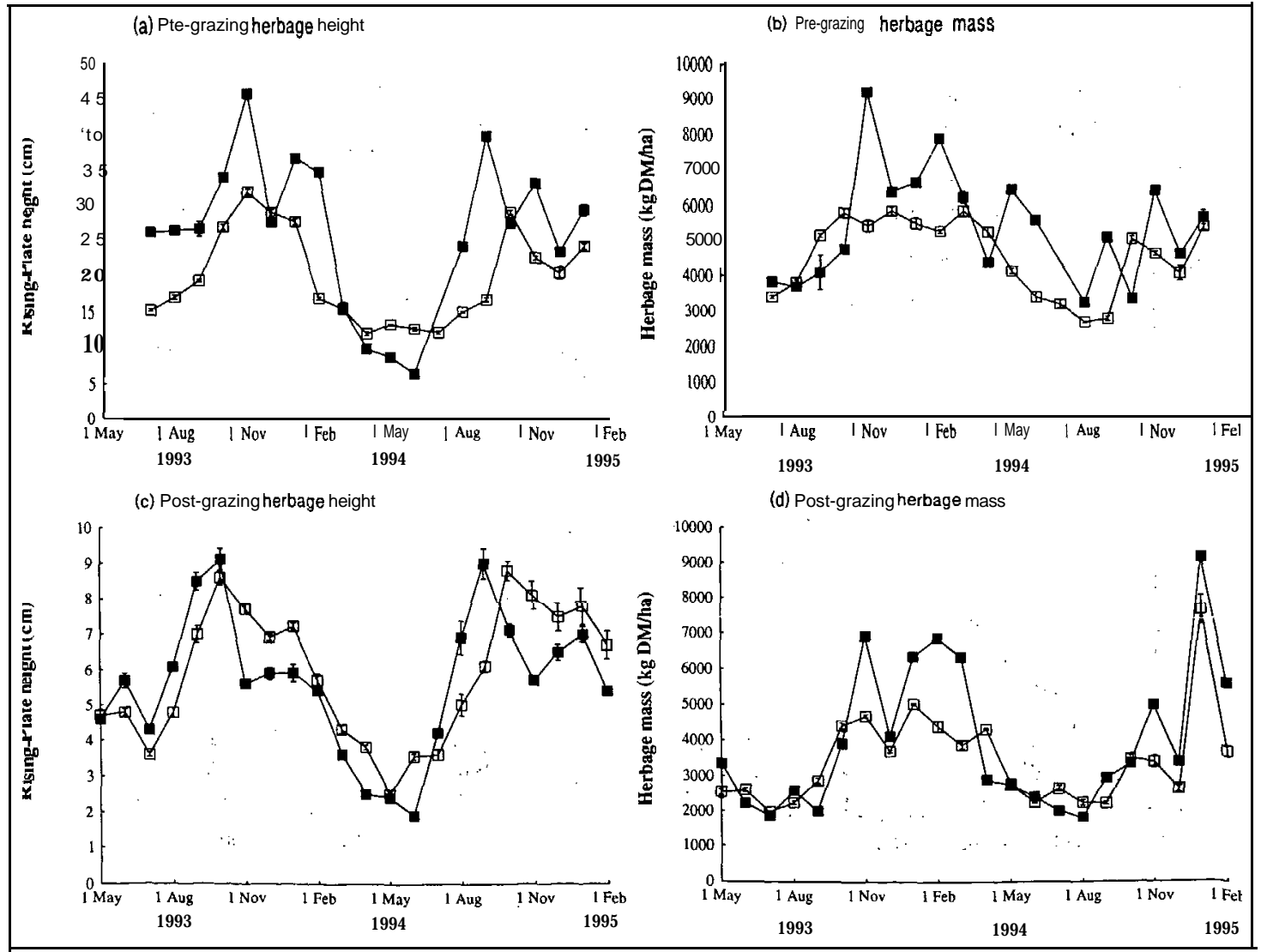


\section{Discussion}

The feedlot diet was formulated to provide a balanced high-energy diet that would promote high LWG (Muir et al. 1992). A feedlot environment also reduces the energy costs of foraging and ensures greater uniformity in diet composition, quality and quantity than is possible with grazing. The maximum LWG that could be sustained by growing steers over a long period was approximately $1 \mathrm{~kg} / \mathrm{hd} / \mathrm{day}$. Muir et al. (1992) recorded gains of $2 \mathrm{~kg} / \mathrm{hd} /$ day in cattle growing from 560 to $760 \mathrm{~kg} \mathrm{LW}$ over 12 weeks, although this may have included compensatory growth. Liveweight gain in studies summarised by Preston \& Willis (1974) ranged from 0.7 to $1.5 \mathrm{~kg} / \mathrm{hd} /$ day on cereal-based diets over periods of up to 1 year. To the authors' knowledge, there are no comparable long-term measurements made on steers that have been fed ad libitum on forage diets, where the confounding influence of compensating gain can be discounted, although shorter-term experiments withadfibitum feeding have been conducted (e.g., Clark 1991).

Even though the LWG of the pasture-fed steers was lower overall than that of the feedlot steers, and varied seasonally, differences between pasture and feedlot in dietary energy concentration, the greater energy costs associated with grazing, or even inherent seasonality in an animals physiological potential for gains do not consistently account for the different patterns of gain. There are two possible explanations for the observed difference between the feedlot and pasture treatment groups, both related to characteristics of the forage diet. Firstly, liveweight is confounded by gut fill and size of the gas\&o-intestinal tract, both of.which can increase as diet quality decreases. The magnitude of these changes can easily mask digesta-free body growth over shortmedium periods of time.

Secondly, in comparison to the feedlot diet, there is variability in the pasture diet, which cannot be avoided. Pasture was allocated at a constant mass per unit LW, and an assumption was made that at high allowances, any change in leaf, stem or dead proportion in the forage offered in autumn would not preclude high intake of green, leafy herbage. However, the assumption that the pre-grazing height and mass criteria set would necessarily allow maximum intake in all seasons, regardless of changes in pasture composition, may not be valid and pasture conditions in autumn may have restricted gain. Herbage height was marginal for red clover-lotus during the period of low LWG in autumn 1994, but not in autumn 1995. Differences in spring and autumn LWGs have been noted before (Reid 1986) and attributed to different maintenance requirements (Marsh 1975), or nutritive value (Beever et al. 1978). At this stage of the trial no explanation completely accounts for the seasonality contrast between feedlot and grazing groups, or between the first and subsequent two autumns. However, changes in forage quality during the year may have acted as a biological trigger to change LWG potential, i.e., seasonality was induced in the grazing treatments but not in the feedlot treatment, in which diet quality was constant.

Translating these results to practice will require, firstly, an identification of the cost, in terms of reduced LWG, or failure to meet specific weight targets at a given age, of not meeting feeding targets for particular periods during growth. Secondly, it is necessary to define whether growth could be deliberately limited during defined periods without any large effect on target weightfor-age criteria by strategic use of compensatory growth. Different options may be appropriate depending on the relative expense of maintaining forage quantity versus maintaining forage quality. Expensive feeding periods for grazing systems to maximise daily LWG are winter, when low pasture growth rates necessitate provision of large areas (i.e., low stocking rates) to satisfy feed allocation targets, and late spring-summer, when low utilisation to ensure high daily herbage intake inevitably leads to poor quality and composition of pasture. The difference between feedlot and pasture diets generated a large difference in the overall gain, and the seasonal patterns of gain. However, the difference in LWG between the two pasture diets caused a smaller difference, and an interim conclusion would be that the use of specialist high quality pasture species, and the cost associated with establishing and maintaining them, cannot be justified by the extra LWG achieved, at least for long-term feeding. However, strategic use of high quality species, or of energy-dense diets, to overcome specific quality or quantity limitations of a resident pasture-based system, may be highly successful.

\section{Con c l u si o n s}

Steers fed a high concentrate diet grew faster than steers fed. forage diets. Despite the generous feed allocation, grazing steers have shown seasonality in growth, yet for substantial parts of the year, LWG of grazing steers was similar to that of the feedlot steers. There is no simple explanation for these effects. Possible influences of limiting pasture height during. autumn 1994, and the transfer of steers to a new location seem unlikely because a similar pattern of depressed growth occurred in autumn 1995 in the absence of both of these factors. A difference in feed quality between the feedlot diet and either pasture diet in autumn may account for the difference, yet the contrast between a pure-legume diet $(\mathrm{HQ})$ and a dominant grass diet (R) 
did not affect this seasonal stasis. Full analysis of these data in relation to daily feed intake of all treatments and final weight for age and carcass composition data will enable a more critical interpretation of observations to date.

\section{ACKNOWLEDGMENTS}

C.B. Anderson and T.R.N. Berquist at Palmerston North and N.B. Smith and G.J. Wallace at Poukawa for technical assistance.

\section{REFERENCES}

Beever, D.E.; Terry, R.A.; Cammell, S.B.; Wallace, A.S. 1978. The digestion of spring and autumn harvested perennial ryegrass by sheep. Journal of agricultural science, Cambridge 90: 463-470.

Clark, D.A. 1991. Pastures and beef flavour. Report to AGMARDT.

Clark, D.A.; Anderson, C.B.; Hongwen, Gao 1990. Liveweight gain and intake of Friesian bulls grazing 'Grasslands Puna' chicory (Cichorium intybus L.) pasture. New Zealand journal of agricultural research 33: 219-224.

Cosgrove, G.P.; Brougham, R.W. 1988. Pasture strategies for dairy beef production. Proceedings of the New Zealand Grassland Association 49: 5762.

Croy, B.G.; Weeda, W.C. 1974. Beef production on pasture and lucerne. Proceedings of the New Zealand Grassland Association 36: 73-79.

Forgie, R. 1993. A meat company approach to the North Asia market. Proceedings of the Central Districts Sheep \& Beef Cattle Farmers Conference 2: 105109 .

Frame, J. 1987. Efficient beef production from grass. British Grassland Society Occasional Symposium, No. 22. J. Frame (Ed.), 310 pp.

Goold, G.J., Weeda, W.C. 1985. The value of regrassing with improved pasture cultivars in Waikato. Proceedings of the New Zealand Grassland Association 46: 179-183.

Marsh, R. 1975. A comparison between spring and autumn pasture for beef cattle at equal grazing pressure. Journal of the British Grassland Society 30: $165-170$.
McCall, D.G.; Marshall, P.R. 1991. Factors affecting beef finishing efficiency on pasture. Proceedings of the New Zealand Society of Animal Production 51: 453-457.

Morris, C.A.; Barker, R.L.; Carter, A.H.; Hickey, SM. 1990. Evaluation of eleven cattle breeds for crossbred beef production: carcass data from males slaughtered at two ages. Animalproduction 50: 7992.

Muir, P.D.: Cruickshank, G.J.; Smith, N.B.; MacLean, K.S.; Wallace, G.J. 1992. A comparison of grain and pasture finishing of heavyweight cattle. Proceedings of the New Zealand Society of Animal Production 52: 93-95.

Pleasants, A.B.; McCall, D.G.; Parminter, T.G.; Sheath, G.W. 1992. A Question of Quality Beef. The New Zealand meat producer 20(4):13-1 4 .

Preston, T.R., Willis, M.B. 1974. Intensive Beef Production, Chapter 9. Growth and Efficiency: Nutrition. Pergamon Press.

Purchas, R. 1993. Definition and objective measurement of quality beef. Proceedings of the Central Districts Sheep \& Beef Cattle Farmers Conference 2: 101104

Reid, T.C. 1986. Comparison of autumn/winter with spring pasture for growing beef cattle. Proceedings of the New Zealand Society of Animal Production 46: $145-147$.

Rollo, M.D.: McCall, D.G.; Boom, C.J.; Sheath, G.W. 1995. Evaluation of a beef growth model for use in beef finishing decision support. Proceedings of the New Zealand Grassland Association 57: in press.

Webby, R.W.; Pleasants, A.B.; Greaves, L.A. 1993. Variation in cattle liveweights at marketing. Proceedings of the New Zealand Grassland Association 55: 155-1 59.

Webby, R.W.; Sheath, G.W.; Boom, C.J. 1990. Performance of new cultivars in a hill country finishing system. Proceedings of the New Zealand Grassland Association 51: 151-155.

Wright, L. 1993. Costs of production for heavyweight steers vs bull beef. Proceedings of the Central Districts Sheep \& Beef Cattle Farmers Conference 2: $111-121$. 